Proceedings of the 2006 ACEEE Summer Study on Energy Efficiency in Buildings, Pacific Grove, CA, August 13-18, 2006

\title{
Participation through Automation: Fully Automated Critical Peak Pricing in Commercial Buildings
}

\author{
Mary Ann Piette, David S. Watson, Naoya Motegi, Sila Kiliccote \\ Lawrence Berkeley National Laboratory
}

\author{
Eric Linkugel \\ Pacific Gas and Electric Company
}

This work described in this report was coordinated by the Demand Response Research Center and funded by the California Energy Commission, Public Interest Energy Research Program, under Work for Others Contract No.150-99-003, Am \#1 and by the U.S. Department of Energy under Contract No. DE-AC0205CH11231. 


\title{
Participation through Automation: Fully Automated Critical Peak Pricing in Commercial Buildings
}

\author{
Mary Ann Piette, David Watson, Naoya Motegi, Sila Kiliccote \\ Lawrence Berkeley National Laboratory \\ Eric Linkugel, Pacific Gas and Electric Company
}

\begin{abstract}
California electric utilities have been exploring the use of dynamic critical peak prices (CPP) and other demand response programs to help reduce peaks in customer electric loads. CPP is a tariff design to promote demand response. Levels of automation in DR can be defined as follows. Manual Demand Response involves a potentially labor-intensive approach such as manually turning off or changing comfort set points at each equipment switch or controller. Semi-Automated Demand Response involves a pre-programmed demand response strategy initiated by a person via centralized control system. Fully Automated Demand Response does not involve human intervention, but is initiated at a home, building, or facility through receipt of an external communications signal. The receipt of the external signal initiates pre-programmed demand response strategies. We refer to this as Auto-DR.

This paper describes the development, testing, and results from automated CPP (Auto$\mathrm{CPP}$ ) as part of a utility project in California. The paper presents the project description and test methodology. This is followed by a discussion of Auto-DR strategies used in the field test buildings. We present a sample Auto-CPP load shape case study, and a selection of the AutoCPP response data from September 29, 2005. If all twelve sites reached their maximum saving simultaneously, a total of approximately $2 \mathrm{MW}$ of DR is available from these twelve sites that represent about two million $\mathrm{ft}^{2}$. The average $\mathrm{DR}$ was about half that value, at about $1 \mathrm{MW}$. These savings translate to about 0.5 to $1.0 \mathrm{~W} / \mathrm{ft}^{2}$ of demand reduction. We are continuing field demonstrations and economic evaluations to pursue increasing penetrations of automated DR that has demonstrated ability to provide a valuable DR resource for California.
\end{abstract}

\section{Background}

California electric utilities have been exploring the use of critical peak prices (CPP) and other demand response programs to help reduce peak demands from customer electric loads. CPP is a form of price-responsive demand response. Recent evaluations have shown that customers have limited knowledge of how to operate their facilities to reduce their electricity costs under CPP (Quantum Consulting and Summit Blue, 2004). While lack of knowledge of how to develop and implement DR control strategies is a barrier to participation in DR programs like CPP, another barrier is the lack of automation in DR systems. Most DR activities are manual and require people to first receive emails, phone calls, and pager signals, and second, for people to act on these signals to execute DR strategies.

Levels of automation in DR can be defined as follows. Manual Demand Response involves a labor-intensive approach such as manually turning off or changing comfort set points at each equipment switch or controller. Semi-Automated Demand Response involves a preprogrammed demand response strategy initiated by a person via centralized control system. 
Fully-Automated Demand Response does not involve human intervention, but is initiated at a home, building, or facility through receipt of an external communications signal. The receipt of the external signal initiates pre-programmed demand response strategies. We refer to this as Auto-DR. One important concept in Auto-DR is that a homeowner or facility manager should be able to "opt out" or "override" a DR event if the event comes at time when the reduction in end-use services is not desirable. Participation of more then 30 large facilities in the last three years of demonstrations has shown that the automation can be provided with minimal resistance from facility operators.

The PIER Demand Response Research Center conducted a series of tests during the summers of 2003, 2004, and 2005. The objectives of these tests were two fold. First, we sought to develop and evaluate communications technology to send DR signals to commercial buildings. This was necessary because buildings use controls with diverse protocols and communication capabilities. Second, we sought to understand and evaluate the type of control strategies facility owners and managers would be willing to test in their buildings. During these past three years we have evaluated Auto-DR in 28 facilities; the average demand reductions were about $8 \%$ over the three to six hour DR events. Many electricity customers have suggested that automation will help them institutionalize and "harden" their electric demand savings, improving overall response and repeatability. The evaluation of the California's 2004 DR programs found that ten to fifteen of the sites that participated in their study could not participate in the DR event because the person in charge of the demand reduction was not in the facility on the day of the event (Quantum Consulting and Summit Blue, 2004).

Table 1 shows the number of sites that participated in each year's field tests along with the average and maximum peak demand savings. The electricity savings data are based on weather sensitive baseline models developed for each building that predicts how much electricity each site would have used without the DR strategies. Further details about this research are available in previous reports (Piette et all, 2005a and b). One key distinction between the 2005 and the previous tests is that the 2005 sites were actually on a CPP tariff, while the 2003 and 2004 tests used fictitious prices and there was no actual economic incentive for the sites. The "fictitious" test consisted of an actual shed based on fictitious prices. There were no DR economics incentives. The sites were willing to conduct the DR to understand their DR capability and automation infrastructure.

Table 1. Average and Maximum Peak Demand Savings during Automated DR Tests

\begin{tabular}{|c|c||c|c|c|}
\hline $\begin{array}{c}\text { Results by } \\
\text { Year }\end{array}$ & \# of sites & $\begin{array}{c}\text { Duration of } \\
\text { Event (Hours) }\end{array}$ & $\begin{array}{c}\text { Average Savings } \\
\text { During (\%) }\end{array}$ & $\begin{array}{c}\text { Highest Max } \\
\text { Hourly Savings (\%) }\end{array}$ \\
\hline $\mathbf{2 0 0 3}$ & 5 & 3 & 8 & 28 \\
\hline $\mathbf{2 0 0 4}$ & 18 & 3 & 7 & 56 \\
\hline $\mathbf{2 0 0 5}$ & $12 *$ & 6 & 9 & 38 \\
\hline
\end{tabular}

* Some of the sites recruited were not successful during the 2005 CPP events because of delays with advanced meters and control work, but are expected to be ready for the 2006 tests.

The focus of the rest of this paper is the design and results from the 2005 Auto-CPP field tests, with some additional comments about the previous years' tests. The next section describes the Auto-CPP project description and test methodology. This is followed by a discussion of Auto-DR strategies used in the field test buildings. We then present a sample Auto-CPP load shape case study, and a selection of the Auto-CPP DR data from September 29, 2005. The 
summary section provides an overview of key findings. Since the buildings only participated within the program during the later DR events of the summer 2005, we do not have detailed economics on the impact of CPP. Each site, however, saved money.

\section{Automated CPP Project Description}

PG\&E's critical peak pricing (CPP) program is a voluntary alternative to traditional timeof-use rates. The CPP program only operates during the summer months (May 1 through October 31). Under the program, PG\&E charges program participants' higher prices for power on up to 12 hot afternoons between May 1 and October 31. Manual CPP customers are notified by email and phone by $3 \mathrm{pm}$ the previous day that the following day is a CPP day. The customer sees lower electricity costs on non-CPP days. The price of electricity rises on maximum of 12 hot days, with the DR event triggered by temperature. The additional energy charges for customers on this tariff on CPP operating days are as follows (Figure 1):

- CPP Moderate-Price Period Usage: The electricity charge for usage during the CPP Moderate-Price Period was three times the customer's summer part-peak energy rate under their otherwise-applicable rate schedule multiplied by the actual energy usage. The CPP Moderate-Price period was from 12:00 Noon to 3:00 PM on the CPP operating days.

- CPP High-Price Period Usage: The total electricity charge for usage during the CPP High-Price Period was five times the customer's summer on-peak energy rate under their otherwise-applicable rate schedule multiplied by the actual energy usage. The CPP HighPrice period was from 3:00 PM to 6:00 PM on the CPP operating days.

Figure 1. Critical Peak Pricing Tariff

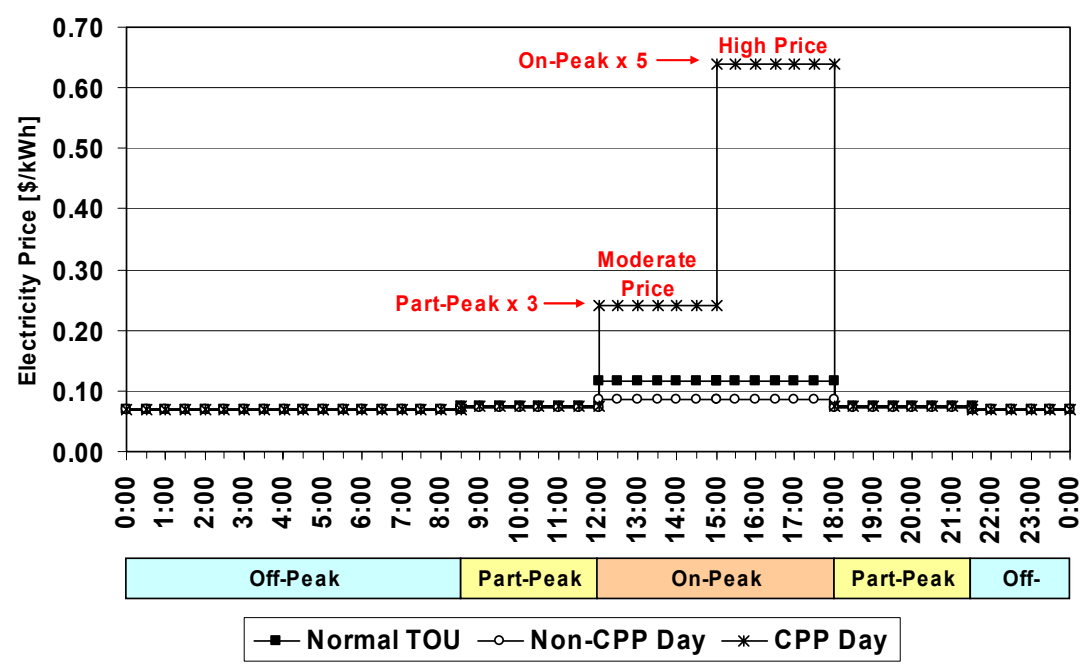

The 2005 Auto-DR project design of was a collaboration between LBNL, the DRRC, and PG\&E. PG\&E had offered voluntary critical peak pricing in 2004, with over 250 sites participating. We recruited $15 \mathrm{PG} \& \mathrm{E}$ customer facilities to participate in fully automated response critical peak pricing. There were three categories of recruits. First, five of the sites had participated in the 2004 Auto-DR tests and were willing to move from the fictitious tests to the 
actual tariff. Second, we worked with the PG\&E Customer Account representatives to recruit two sites that had been on CPP to include them in the Auto-CPP tests. Third, eight sites were recruited for the 2005 tests that had not been on CPP or had not participated in the previous Auto-DR tests.

Demand Response Automation Server. PG\&E sent the Critical Peak Price signals to each participating facility using the Demand Response Automation Server developed by LBNL and Akuacom. The Automation Server communicated via XML with PG\&E DR communications system, Interact II. Qualified sites were configured to respond to automated price signals transmitted over the Internet using relays and gateways that send standardized signals to the energy management control system (EMCS). A few sites used the day-ahead automation notification for their pre-cooling strategies. Most of the sites used the signal in real time that alerted them at noon on the CPP day that the event was triggered. During the 2005 summer test period, as the electricity price increases during a CPP event, pre-selected electric loads were automatically curtailed based on each facility's control strategy. The automation server uses the public Internet and private corporate and government intranets to communicate CPP event signals that initiate reductions in electric load in commercial buildings. The researchers worked with the facility managers to evaluate the control strategies programmed in the energy management and control systems (EMCS), which excecuted pre-determined demand response strategies at the appropriate times.

Connectivity was provided by either an Internet gateways or Internet relays (as shown in Figure 2). The Internet gateways typically connect the Internet communication protocol (TCP/IP) to the protocol of a given EMCS. This means that a different Internet gateway type is usually required to communicate with each different EMCS brand or product line. Gateways provide a variety of functions further described in Piette et al. (2005). An Internet relay is a device with relay contacts that can be actuated remotely over a LAN, WAN or the Internet using Internet Protocols (IP). The Internet is based on a standard protocol (TCP/IP) and all EMCS can sense the state of relay contact closures (regardless of their particular EMCS protocol). Because of this, Internet relays can be used on virtually any commercial building that has a standard connection to the Internet. Internet connectivity directly to the EMCS is not required. 
Figure 2. Demand Response Automation Server and Building Communication Systems

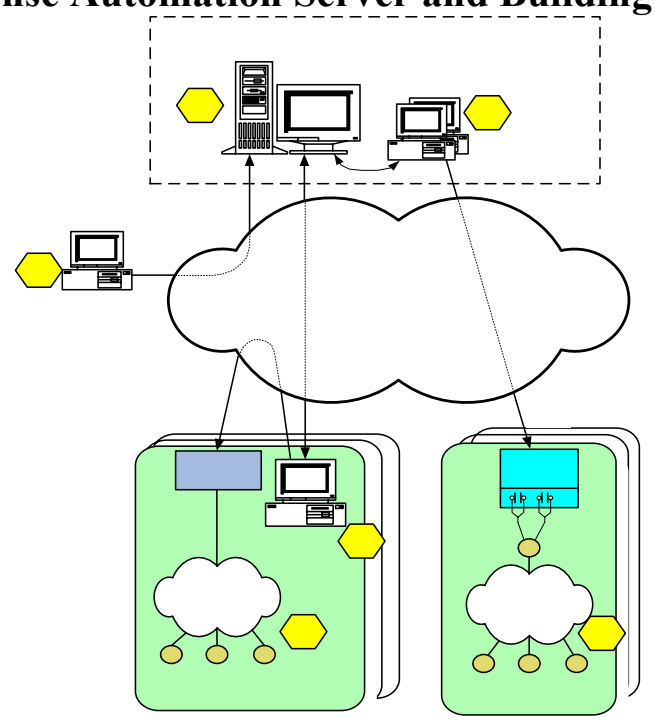

The four elements of the diagram are as follows:

1. PG\&E uses their standard InterAct II system to notify the Automation Server of an upcoming CPP event (notification occurs day-ahead).

2. The Automation Server posts two pieces of information on its Web services server:

$\circ$ There is a pending event. This is posted immediately upon receipt from PG\&E at approximately 3:00 PM the day ahead.

$\circ$ There is an active event of a given level. Moderate-level demand response events are posted between 12:00 - 3:00 PM. High-level demand response events are posted between 3:00 PM-6:00 PM on the day of the event.

3. Polling clients request information each minute. Logic software determines actions based upon latest information polled from the Automation Server. Actions are initiated based on predetermined logic.

4. Energy management control system (EMCS) carries out predetermined demand response control commands.

\section{Evaluation Methodology}

LBNL developed an electric load shape baseline model to estimate the demand shed from the DR strategies for each building. First we collected the electric consumption data from Interact for each site. We subtracted the actual metered electric consumption from the baselinemodeled consumption to derive an estimate of demand savings for each 15-minute period. The model is described in previous papers (Piette et al, 2005). PG\&E uses a baseline for the CPP evaluation. The demand response strategy was considered effective if in either or both of the moderate price and the high price period, the average power savings over the 3-hour period was larger than the average of the standard error in the baseline model. For each building we derived the hourly electric load savings, percent savings in whole-building load, and power density reduction $\left(\mathrm{W} / \mathrm{ft}^{2}\right)$. Sample results for the Auto-CPP events are shown below. 
The CPP baseline used by PG\&E does not include weather data, but is based on the average hourly load shape of 3 highest consumption days in the last 10 working days (excluding holidays). The baseline algorithm considers the site electric consumption from the period of noon to $6 \mathrm{pm}$ to choose the highest 3 days. CPP event days are excluded from the reference days. The CPP baseline estimate may be lower than the actual demand if the site's demand is weather-sensitive, since a CPP day typically occurs on a higher temperature day. If the ten previous working days were cooler than the CPP day, the baseline will be lower than weather normalized baseline.

There are a few other features about project that we do not have space to review in this paper. The evaluation included post-event surveys to determine how well each strategy performed and if there were any outstanding issues in the DR control strategies. The evaluation also examined the cost to program control strategies in the EMCS and to connect the Internet gateways and relays.

\section{Auto-DR Field Test Results}

In 2003, 2004, and 2005 we conducted Automated DR tests in 28 buildings listed in Table 2 below. Table 3 shows the entire list of sites and which years they participated. The tests included numerous building types such as office buildings, a high school, a museum, laboratories, a cafeteria, data centers, a postal facility, a library, retail chains, and a supermarket. The buildings range from large campuses, to small research and laboratory facilities. The table lists the DR control strategies used at each building. The full reports from the Auto-DR field tests describe these strategies in greater details, and they are also discussed in Watson et al. (2006).. The global zone temperature adjustment was the most commonly used strategy, though 16 other strategies are listed. Nearly all of these strategies were based on direct connections to the EMCS. Further details on pre-cooling research, which may prove to be an important DR control strategy, are presented in Peng et al, (2004 and 2005). 
Table 2. Building Type, Size, Year in Auto-DR, and DR Control Strategy Used

\begin{tabular}{|c|c|c|c|c|c|c|c|c|c|c|c|c|c|c|c|c|c|c|c|c|c|c|c|c|c|}
\hline & & & & Par & ticipat & tion & & & & & & & $\mathrm{HV}$ & $\mathrm{AC}$ & & & & & & & & Ligh & ht, M & lisc. & \\
\hline & Building use & $\begin{array}{c}\text { Total } \\
\text { conditioned } \\
\text { area } \\
\end{array}$ & $\begin{array}{l}\text { \# of } \\
\text { bldg }\end{array}$ & 2003 & 2004 & 2005 & 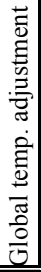 & 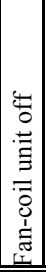 & 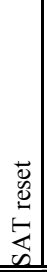 & 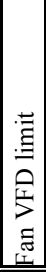 & 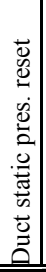 & 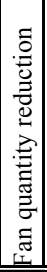 & 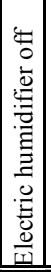 & 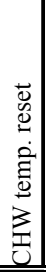 & 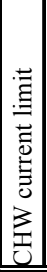 & 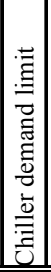 & 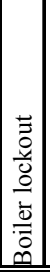 & 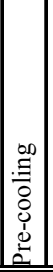 & 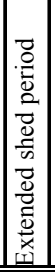 & 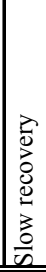 & 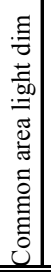 & 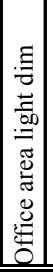 & 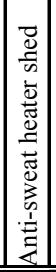 & 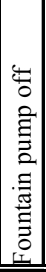 & 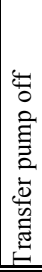 \\
\hline 300 CapMall & Office & 383,000 & 1 & & $\mathrm{X}$ & & $\mathrm{X}$ & & & $\mathrm{X}$ & & $\mathrm{X}$ & & $\mathrm{X}$ & & & & & & & & & & $\mathrm{X}$ & \\
\hline ACWD & Office, lab & 51,200 & 1 & & & $\mathrm{X}$ & $\mathrm{X}$ & & $\mathrm{X}$ & & $\mathrm{X}$ & & & $\mathrm{X}$ & $\mathrm{X}$ & & $\mathrm{X}$ & & $\mathrm{X}$ & & & & & & \\
\hline Albertsons & Supermarket & 50,000 & 1 & $\mathrm{X}$ & & & & & & & & & & & & & & & & & $\mathrm{X}$ & & $\mathrm{X}$ & & \\
\hline B of A & Office, data center & 708,000 & 4 & $\mathrm{X}$ & $\mathrm{X}$ & $\mathrm{X}$ & & & $\mathrm{X}$ & $\mathrm{X}$ & $\mathrm{X}$ & & & $\mathrm{X}$ & $\mathrm{X}$ & & & & & & & & & & \\
\hline Chabot & Museum & 86,000 & 2 & & & $\mathrm{X}$ & $X$ & & & & & & & & & & & $\mathrm{X}$ & & & & & & & \\
\hline Cal EPA & Office & 950,000 & 1 & & $\mathrm{X}$ & & & & & & $\mathrm{X}$ & & & & & & & & & & $\mathrm{X}$ & $\mathrm{X}$ & & & \\
\hline CETC & Research facility & 18,000 & 1 & & $\mathrm{X}$ & & & & & & & $\mathrm{X}$ & $\mathrm{X}$ & & & & & & & & & & & & \\
\hline Cisco & Office, tech lab & $4,466,000$ & 24 & & $\mathrm{X}$ & & $\mathrm{X}$ & $\mathrm{X}$ & & & & & & & & & $\mathrm{X}$ & & & & $X$ & $\mathrm{X}$ & & & \\
\hline 2530 Arnold & Office & 131,000 & 1 & & $X$ & $\mathrm{X}$ & $\mathrm{X}$ & & & & & & & & & & & & & $\mathrm{X}$ & & & & & \\
\hline 50 Douglas & Office & 90,000 & 1 & & $\mathrm{X}$ & $\mathrm{X}$ & $\mathrm{X}$ & & & & & & & & & & & & & $\mathrm{X}$ & & & & & \\
\hline Echelon & Corporate Headquarter & 75,000 & 1 & & $\mathrm{X}$ & $\mathrm{X}$ & $\mathrm{X}$ & & $\mathrm{X}$ & & $\mathrm{X}$ & $\mathrm{X}$ & & & & & & & & & $\mathrm{X}$ & $\mathrm{X}$ & & & \\
\hline GSA 450 GG & Federal office & $1,424,000$ & 1 & & $\mathrm{X}$ & & $\mathrm{X}$ & & & & & & & & & & & & & & & & & & \\
\hline GSA NARA & Archive storage & 202,000 & 1 & & $\mathrm{X}$ & & $\mathrm{X}$ & & & & & & & & & & & & & & & & & & \\
\hline GSA Oakland & Federal office & 978,000 & 1 & $\mathrm{X}$ & $\mathrm{X}$ & & $\mathrm{X}$ & & & & & & & & & & & & & & & & & & \\
\hline Gilead 300 & Office & 83,000 & 1 & & & $\mathrm{X}$ & & & $\mathrm{X}$ & & & & & & & & & & & & & & & & \\
\hline Gilead 342 & Office, Lab & 32,000 & 1 & & & $\mathrm{X}$ & $\mathrm{X}$ & & $\mathrm{X}$ & & & & & & & & & & & & & & & & \\
\hline Gilead 357 & Office, Lab & 33,000 & 1 & & & $\mathrm{X}$ & $\mathrm{X}$ & & $\mathrm{X}$ & & & & & & & & & & & & & & & & \\
\hline Irvington & Highschool & N/A & 1 & & & $\mathrm{X}$ & $\mathrm{X}$ & & & & & & & & & & & $\mathrm{X}$ & & & & & & & \\
\hline IKEA & Retail & 300,000 & 1 & & & $\mathrm{X}$ & $\mathrm{X}$ & & & & & & & & & & & & & & & & & & \\
\hline Kadent & Material process & - & 1 & & $\mathrm{X}$ & & & & & & & & & & & & & & & & & & & & $\mathrm{X}$ \\
\hline LBNL OSF & Data center, Office & 70,000 & 1 & & & $\mathrm{X}$ & $\mathrm{X}$ & & & & & & & & & & & $\mathrm{X}$ & & & & & & & \\
\hline Monterey & Office & 170,000 & 1 & & $\mathrm{X}$ & & & & & & & & & & & & & & & & $\mathrm{X}$ & & & & \\
\hline Oracle & Office & 100,000 & 2 & & & $\mathrm{X}$ & $\mathrm{X}$ & & & & $\mathrm{X}$ & & & & & & & & & & & & & & \\
\hline OSIsoft & Office & 60,000 & 1 & & $\mathrm{X}$ & & $\mathrm{X}$ & & & & & & & & & & & & & & & & & & \\
\hline \begin{tabular}{|l|} 
Roche \\
\end{tabular} & Cafeteria, auditorium & 192,000 & 3 & $\mathrm{X}$ & $\mathrm{X}$ & & & & & & & $\mathrm{X}$ & & & & & & & & & & & & & \\
\hline Target & Retail & 130,000 & 1 & & & $\mathrm{X}$ & & & & & & $\mathrm{X}$ & & & & & & & & & $\mathrm{X}$ & & & & \\
\hline UCSB Library & Library & 289,000 & 3 & $\mathrm{X}$ & $\mathrm{X}$ & & & & & $\mathrm{X}$ & $\mathrm{X}$ & & & & $\mathrm{X}$ & & & & & & & & & & \\
\hline USPS & Postal service & 390,000 & 1 & & $\mathrm{X}$ & $\mathrm{X}$ & & & & & & & & & & $\mathrm{X}$ & & & & $\mathrm{X}$ & & & & & \\
\hline
\end{tabular}

\section{Example of Demand Response from an Office Building}

This section provides an example of the DR electric load shape data for a $130,000 \mathrm{ft}^{2}$ Contra Costa County office building. The graph shows the electric load shape during an actual Auto-CPP event on September 29, 2005. The baseline power peaks around $400 \mathrm{~kW}$, with the weather sensitive LBNL baseline and the PG\&E CPP baseline also shown. The vertical line at each baseline power datum point is the standard error of the regression estimate. The vertical lines at noon, $3 \mathrm{pm}$, and $6 \mathrm{pm}$ indicates price signal changes. The building shed about $20 \%$ of the electric loads for six hours by setting up the zone temperatures from 74 to 76 during the first three hours and 76 to $78 \mathrm{~F}$ during the second three hours. This strategy reduced the wholebuilding power density by an average of $0.8 \mathrm{~W} / \mathrm{ft}^{2}$ during the six hours. 


\section{Figure 3. Baseline and Office Building Electric Load Shape During Auto-DR Event}

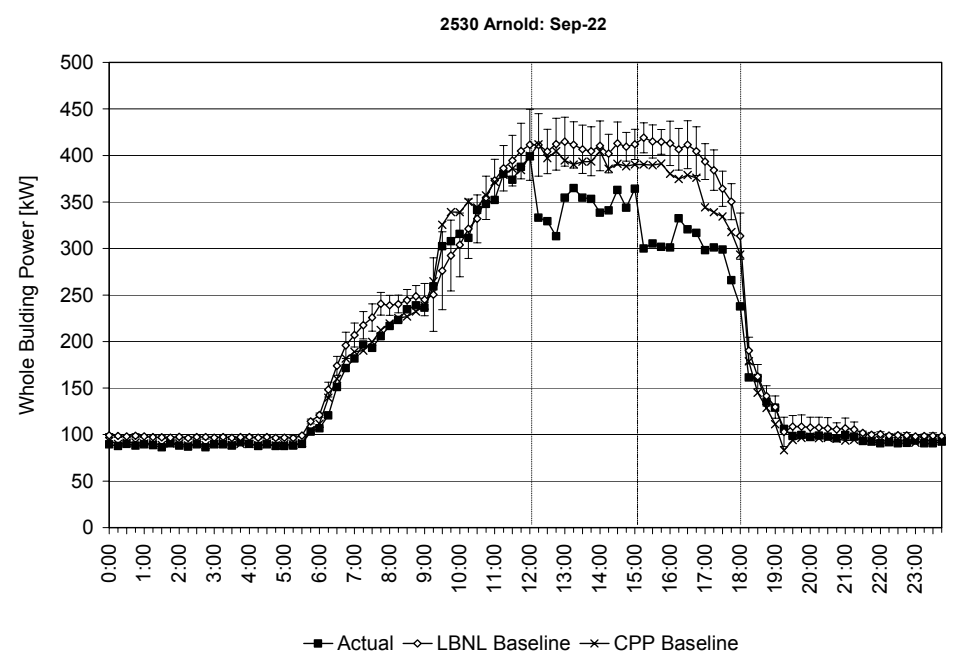

\section{Aggregated Automated Demand Response}

The Auto-CPP tests consisted of seven events that took place from August through November 2005. Configuring many of the sites to participate in the Auto-CPP was time consuming because of complications related to control programming and meter installation delays. Thus, several of the CPP events took place before our sites were configured. To account for this delay, we developed a series of fully automated mock-CPP tests that took place in October and November 2005. These days were not as warm as actual CPP days and the DR events show lower electric savings than we observe on warmer days.

Table 3 shows sample results from eight buildings that participated in Auto-CPP on an actual CPP day. The table lists the average and maximum peak demand savings, whole building percentage savings, and power density savings during the two three-hour price periods: Moderate and High. The average reductions per building ranged from 2 to $184 \mathrm{~kW}$, with maximum savings of 31 to $291 \mathrm{~kW}$. The table shows the total DR (Shed $\mathrm{kW}$ ), whole-building power reduction (WBP \%), and power density reduction $\left(\mathrm{W} / \mathrm{ft}^{2}\right)$. The columns list both the average and maximum savings for the moderate and high priced CPP periods. The maximum is the max demand response in the fifteen-minute monitoring period. Average percentage reductions ranged from zero (negligible) to $28 \%$ savings, and maximum percentage reductions from 3 to $37 \%$. The average power density reductions ranged from 0.02 to $1.95 \mathrm{~W} \mathrm{ft}^{2}$, with maximum demand reductions 0.21 to $4.68 \mathrm{~W} / \mathrm{ft}^{2}$. The Bank of America site dominates the aggregated demand response. 
Table 3. Average Demand Response by Price Period, September $29^{\text {th }}$

\begin{tabular}{|c|c|c|c|c|c|}
\hline & \multirow{2}{*}{ Site Nam } & \multicolumn{2}{|c|}{ Average } & \multicolumn{2}{|c|}{ Max } \\
\hline & & Moderate & & Moderate & High \\
\hline \multirow{8}{*}{$\mathbf{k W}$} & \multirow{4}{*}{$\begin{array}{c}\text { ACWD } \\
\text { f A } \\
\text { Chabot }\end{array}$} & 67 & & 101 & 72 \\
\hline & & 22 & 4 & 132 & 291 \\
\hline & & 2 & & 31 & 88 \\
\hline & & 34 & & 90 & 89 \\
\hline & \multirow{4}{*}{$\begin{array}{l}\text { Echelon } \\
\text { Gilead } 34 \\
\text { Gilead } 3 \\
\text { Target }\end{array}$} & 32 & 9 & 42 & 143 \\
\hline & & 45 & & 73 & 75 \\
\hline & & 48 & & 94 & 150 \\
\hline & & 14 & & 53 & 44 \\
\hline & $(\Delta \mathbf{P})$ & 263 & & 617 & 952 \\
\hline \multirow{8}{*}{$\%$} & \multirow{8}{*}{$\begin{array}{c}\text { ACWD } \\
\text { of A } \\
\text { abot } \\
2530 \text { Arno } \\
\text { helon } \\
\text { Gilead } 34 \\
\text { Gilead } 35 \\
\text { Target }\end{array}$} & $24 \%$ & & $38 \%$ & $23 \%$ \\
\hline & & $0 \%$ & & $3 \%$ & $6 \%$ \\
\hline & & $0 \%$ & & $10 \%$ & $28 \%$ \\
\hline & & $8 \%$ & & $21 \%$ & $21 \%$ \\
\hline & & $9 \%$ & & $12 \%$ & $37 \%$ \\
\hline & & $13 \%$ & & $19 \%$ & $20 \%$ \\
\hline & & $9 \%$ & & $16 \%$ & $25 \%$ \\
\hline & & $4 \%$ & & $15 \%$ & $12 \%$ \\
\hline & $3 \%$ & & $8 \%$ & $12 \%$ \\
\hline & & $9 \%$ & & $17 \%$ & $21 \%$ \\
\hline & \multirow{4}{*}{$\begin{array}{c}\text { WD } \\
\text { B of A } \\
\text { habot }\end{array}$} & 1.53 & & 2.30 & 1.63 \\
\hline & & 0.04 & & 0.21 & 0.47 \\
\hline & & 0.02 & & 0.35 & 1.02 \\
\hline & & 0.26 & & 0.69 & 0.68 \\
\hline & \multirow{4}{*}{$\begin{array}{l}\text { Echelon } \\
\text { Gilead } 342 \\
\text { Gilead } 357 \\
\text { Target }\end{array}$} & 0.43 & 1.45 & 0.56 & 1.91 \\
\hline & & 1.39 & 1.72 & 2.30 & 2.36 \\
\hline & & 1.50 & 1.95 & 2.95 & 4.68 \\
\hline & & 0.13 & 0.30 & 0.48 & 0.40 \\
\hline \multicolumn{2}{|c|}{ Total: $\Sigma(\Delta \mathrm{P}) / \Sigma(\mathrm{A})^{* * *}$} & 0.23 & 0.52 & 0.55 & 0.85 \\
\hline \multicolumn{2}{|c|}{ Average: $\Sigma(\Delta \mathrm{P} / \mathrm{A}) / \mathrm{N}$} & 0.66 & 0.98 & 1.23 & 1.64 \\
\hline
\end{tabular}

*The average of the individual average whole building response and the average of the maximum individual DR results are shown, along with the aggregated shed compared to the total baseline power. **The power densities are also shown for the average of the demand intensities (sum all building densities and divide by the sample size) and the sum of the total area and the total aggregated total demand response.

Figure 4 is an aggregated load shape for eight of the buildings from the fully automated shed on September 29, 2005. The load shape shows a total of about 8 MW. The automated DR provided an average of 263 and $590 \mathrm{~kW}$ in the moderate and high price periods, with maximum savings of 617 and $952 \mathrm{~kW}$, or nearly $1 \mathrm{MW}$ maximum. Most of the buildings report no complaints or comfort issues following our event interviews. The aggregated savings is $3 \%$ during the moderate period, and $8 \%$ during the high price period. 
Figure 4. Automated CPP Aggregated Demand Saving Results, September $29^{\text {th }}$

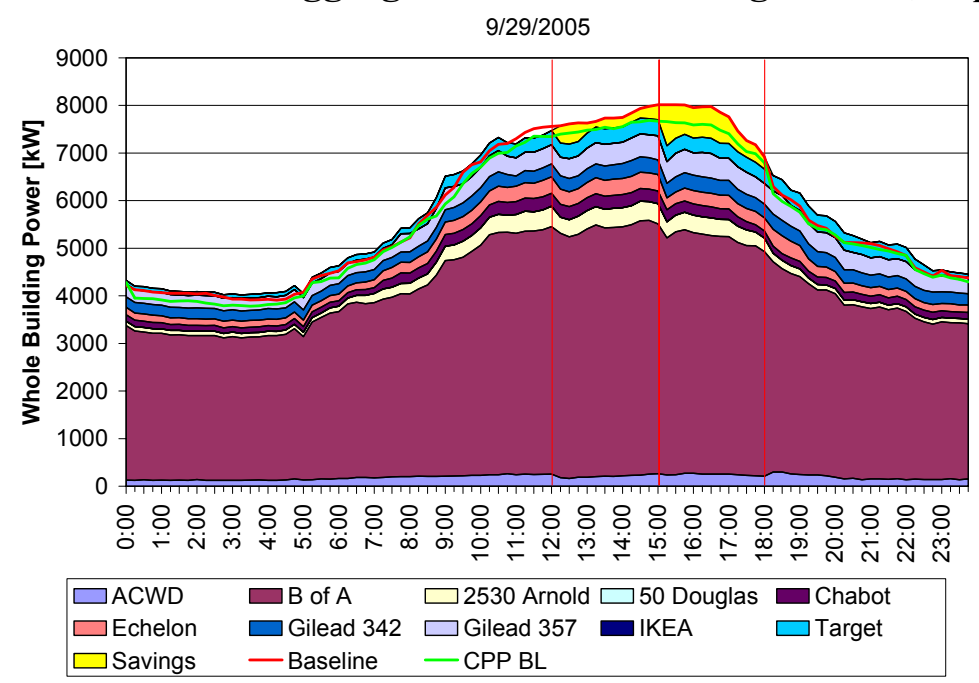

Table 4 shows the baseline peak demand, the maximum 15-minute demand savings for all seven Auto-CPP tests and the non-coincident maximum demand savings. We do not have a day when all sites participated in a DR event. However, if all twelve sites reached their maximum savings simultaneously, a total of approximately $2 \mathrm{MW}$ of demand response is available from these twelve sites that represent about two million $\mathrm{ft}^{2}$. Using the sum of the average demand response for each of the twelve sites results the average demand response was about $1 \mathrm{MW}$. These results indicate that 1 to $2 \mathrm{MW}$ of demand response can be expected for two million $\mathrm{ft}^{2}$ of buildings ( 0.5 to $1.0 \mathrm{~W} / \mathrm{ft}^{2}$ of demand saving) with this type of automation. As mentioned, following each event LBNL interviewed building managers to evaluate if any problems occurred. There were some minor complaints in a few cases. Overall the sites were able to provide good demand response with minimal disruptions. We have begun to explore the costs required to configure the Auto-DR communication systems and program DR control strategies within an EMCS. Initial research suggests we can configure Auto-CPP systems with the existing financial incentives available as part of California utility DR technical assistance funds. Ideally Auto-DR systems would be installed as part of retro-commissioning programs. The knowledge and skills of today's retro-commissioning engineers may be key players in providing building control tune-ups and developing custom DR strategies during field work (Piette et al, 2006). Auto-DR systems rely on a good understanding of HVAC, lighting, and control strategies. 
Table 4. Maximum Demand Response for all Seven Event Days

\begin{tabular}{|c|c|c|c|c|c|c|c|c|c|c|}
\hline & & \begin{tabular}{|l|} 
Aug-08 \\
\end{tabular} & Sep-22 & Sep-29 & Oct-06 & Oct-13 & Oct-25 & Nov-10 & 2004 & Max \\
\hline \multirow[t]{2}{*}{ ACWD } & Baseline Peak kW & & & 330 & 253 & 290 & 238 & & & 330 \\
\hline & Max Shed kW & & & 101 & 74 & 83 & 77 & & & 101 \\
\hline \multirow[t]{2}{*}{ B of $A$} & Baseline Peak kW & & & 5311 & & 5163 & 5053 & & & 5053 \\
\hline & Max Shed kW & & & 291 & & 219 & 552 & & & 552 \\
\hline \multirow[t]{2}{*}{ Chabot } & Baseline Peak kW & & 225 & 308 & 244 & 270 & & & & 308 \\
\hline & Max Shed kW & & 19 & 88 & 36 & 42 & & & & 88 \\
\hline \multirow[t]{2}{*}{2530 Arnold } & Baseline Peak kW & 505 & 419 & 431 & 404 & 406 & 345 & & & 505 \\
\hline & Max Shed kW & 176 & 119 & 90 & 63 & 89 & 40 & & & 176 \\
\hline \multirow[t]{2}{*}{50 Douglas } & Baseline Peak kW & 381 & & & & & 259 & & & 381 \\
\hline & Max Shed kW & 95 & & & & & 78 & & & 95 \\
\hline \multirow[t]{2}{*}{ Echelon } & Baseline Peak kW & & 334 & 403 & 363 & 359 & 304 & & & 403 \\
\hline & Max Shed kW & & 115 & 143 & 132 & 117 & 84 & & & 143 \\
\hline \multirow[t]{2}{*}{ Gilead 342} & Baseline Peak kW & & 288 & 384 & 289 & 340 & 278 & & & 288 \\
\hline & Max Shed kW & & 94 & 75 & 45 & 55 & 80 & & & 94 \\
\hline \multirow[t]{2}{*}{ Gilead 357} & Baseline Peak kW & & & 607 & & 455 & 443 & & & 607 \\
\hline & Max Shed kW & & & 150 & & 119 & 145 & & & 150 \\
\hline \multirow[t]{2}{*}{ IKEA } & Baseline Peak kW & & & & & 1982 & 1803 & & & 1982 \\
\hline & Max Shed kW & & & & & 321 & 223 & & & 321 \\
\hline \multirow[t]{2}{*}{ Oracle } & Baseline Peak kW & & & & & & & 507 & & 507 \\
\hline & Max Shed kW & & & & & & & 65 & & 65 \\
\hline \multirow[t]{2}{*}{ Target } & Baseline Peak kW & & 314 & 364 & 328 & 341 & 296 & & & 341 \\
\hline & Max Shed kW & & 52 & 53 & 60 & 64 & 49 & & & 64 \\
\hline \multirow[t]{2}{*}{ USPS* } & Baseline Peak kW & & & & & & & & 1483 & 1483 \\
\hline & Max Shed kW & & & & & & & & 333 & 333 \\
\hline \multirow[t]{2}{*}{ Total } & Baseline Peak kW & 886 & 1579 & 8138 & 1881 & 9608 & 9020 & 507 & 1483 & 12189 \\
\hline & Max Shed kW & 272 & 399 & 992 & 410 & 1108 & 1329 & 65 & 333 & 2182 \\
\hline
\end{tabular}

* 2004 data (Oct-13) is used for USPS because USPS failed to conduct demand shed in 2005.

\section{Summary and Future Directions}

The Auto-CPP tests in 2005 have demonstrated the technical feasibility of fully automated DR. While there are considerable challenges in Auto-DR in general and Auto-CPP specifically, the research demonstrates that this can be done with reasonable levels of effort with today's technology. New knowledge on what strategies are available for different types of buildings has been obtained and is the subject of another ACEEE paper (Watson et al, 2006).

During 2006 we will be pursing a larger number of tests throughout California. The research may also move beyond CPP into other DR programs such as demand bidding. The primary objective of this new research will be to better understand the economics of installing and configuring automated systems, exploring connectivity and control strategies in more building types, including industrial facilities, and evaluating the peak demand reduction levels for different weather. We are also interested in "heat storm" performance that moves beyond single day DR participation, to several hot days in a row.

In the long term this research aims at transform communications in commercial and industrial facilities to explore literally "connecting" the demand and supply side systems with the technologies and approaches explored in this project. Our goal is to understand how to configure buildings to be "DR Ready" in a low cost way, developing requirements for new buildings through future codes and embedding such communications directly into future EMCS. Additional research is also needed to integrate price and reliability DR signals, which we believe can co-exist on similar communications systems. Finally, there is a need to better understand 
advanced controls for simultaneous use applications of energy efficiency and demand response. We need to define explicit "low power" building operating modes for DR events. Daily advanced energy efficient operations with granular controls provide the best starting point for DR capability. New technologies such as dimmable ballasts and wireless HVAC control are likely to provide such new levels of granularity that can be optimized to provide both daily and enable advanced DR strategies. Along with such new technology is the need for improved energy management and financial feedback systems. As the DR economics mature, better realtime economic feedback is needed if energy managers and facility operators are going to understand the value of participating in DR events.

\section{Acknowledgements}

The authors are grateful for the extensive support from numerous individuals who assisted in this project. Many thanks to the engineers and staff at each building site. Special thanks to Ron Hofmann for his conceptualization of this project and ongoing technical support. Thanks also to Laurie ten Hope, Mark Rawson, and Dave Michel at the California Energy Commission. Thanks also to the Pacific Gas and Electric Company who funded the Automated CPP research. This work described in this report was coordinated by the Demand Response Research Center and funded by the California Energy Commission, Public Interest Energy Research Program, under Work for Others Contract No.150-99-003, Am \#1 and by the U.S. Department of Energy under Contract No. DE-AC02-05CH11231.

\section{References}

Piette, Mary Ann, David Watson, Naoya Motegi, Norman Bourassa and Christine Shockman. 2005a. "Findings from the 2004 Fully Automated Demand Response Tests in Large Facilities” September. CEC-500-03-026. LBNL-58178. Available at http://drrc.lbl.gov/drrc-pubs1.html

Piette, Mary Ann, Osman Sezgen, David Watson, Naoya Motegi, and Christine Shockman. 2005b. "Development and Evaluation of Fully Automated Demand Response in Large Facilities”, January. CEC-500-2005-013. LBNL-55085. Available at http://drrc.lbl.gov/drrc-pubs1.html

Piette, Mary Ann, David Watson, Naoya Motegi, Sila Kiliccote, and Peng Xu. 2006. Automated Critical Peak Pricing Field Tests: Program Description and Results. Report LBNL-59351. March.

Piette, M. A., D. Watson, N. Motegi, S. Kiliccote, and P. Xu. January 2006. Automated Critical Peak Pricing Field Tests: Program Description and Results. Report LBNL-59351

Quantum Consulting, Inc. and Summit Blue LCC. 2004. Working Group 2 Demand Response Evaluation - Program Year 2004. Prepared by Working Group 2 Measurement and Evaluation Committee, December. 
Watson, David S., Naoya Motegi, Mary Ann Piette, Sila Kiliccote. 2006. Automated Demand Response Control Strategies in Commercial Buildings, Forthcoming Proceedings of 2006 ACEEE Summer Study on Energy Efficiency in Buildings. Pacific Grove, CA. Forthcoming.

$\mathrm{Xu}$, Peng, Philip Haves. 2005. Case Study of Demand Shifting With Thermal Mass in Two Large Commercial Buildings. ASHRAE Transactions. LBNL-58649.

Xu, Peng, Philip Haves, and Mary Ann Piette, and James Braun. 2004. Peak Demand Reduction from Pre-cooling with Zone Temperature Reset of HVAC in an Office. Proceedings of 2004 ACEEE Summer Study on Energy Efficiency in Buildings. Pacific Grove, CA. LBNL-55800. 